\title{
Rancang Bangun Mesin Pencoak Pipa (Pipe Notcher) Multi Dimensi
}

\author{
Iswanto $^{1)^{\star}}$, Herman $^{2)}$, Edi Widodo ${ }^{3)}$, A'rasy Fahruddin $^{4)}$ \\ 1, 2) Jurusan Teknik Mesin, Universitas Muhammadiyah Sidoarjo \\ Jl. Mojopahit 666 B Sidoarjo 61215, \\ Email: iswanto@umsida.ac.id, herman.cungkrink@gmail.com \\ ${ }^{3}$ Jurusan Teknik Mesin, Universitas Brawijaya \\ Jl. Veteran Malang 65145, \\ Email: ediwidodo@umsida.ac.id \\ 4) Jurusan Teknik Mesin, Institut Teknologi Sepuluh Nopember \\ Jl. Teknik Kimia Surabaya 60111, \\ Email: rudin.ub@gmail.com
}

doi: https://doi.org/10.24843/METTEK.2020.v06.i02.p05

\begin{abstract}
Abstrak
Mesin pencoak pipa (pipe notcher) yang ada di pasaran saat ini harganya cukup mahal sehingga banyak bengkel-bengkel kecil masih menggunakan cara konvensional untuk melakukan pencoakan pipa. Cara yang biasa digunakan adalah dengan menggunakan gerinda tangan, sehingga membutuhkan waktu yang lama dan hasilnya kurang presisi. Untuk itu pada penelitian ini dirancang mesin pencoak pipa dengan memanfaatkan sabuk amplas sebagai V-belt yang dihubungkan dengan poros dan digerakkan oleh motor listrik. Kemudian benda kerja didekatkan pada poros matras dan selanjutnya ditekan maju sampai terbentuk profil yang diinginkan. Rancang bangun mesin pencoak pipa multi dimensi ini terbagi dalam tiga tahap. Tahap pertama konsep desain dan perencanaan komponen, dilanjutkan dengan tahap pembuatan dan terakhir adalah pengujian mesin. Dari hasil rancang bangun diperoleh bahwa mesin pencoak pipa multi dimensi ini menggunakan motor listrik $0,5 \mathrm{HP}$ dan putaran $1400 \mathrm{rpm}$ sedangkan rangka mesin menggunakan besi siku ukuran $4 \times 4 \mathrm{~cm}$. Setelah dilakukan pengujian, mesin dapat bekerja dengan baik. Untuk mencoak pipa dengan diameter 3/4 inch dibutuhkan waktu selama 0,335 menit, sedangkan untuk pipa ukuran 1 inch membutuhkan waktu selama 1,075 menit. Sedangkan profil yang dibuat menggunakan mesin ini mampu membentuk sudut antara $0^{\circ}$ sampai dengan $30^{\circ}$.
\end{abstract}

Kata kunci: Rancang bangun, mesin pencoak pipa, sabuk amplas

\begin{abstract}
Pipe notcher on the market today are quite expensive so that many small workshops still use the conventional method for cutting special pipe profiles. The method commonly used is to use hand grinding, so it takes a long time and the results are less precise. For this reason, in this study was designed a pipe notcher machine using the sandpaper belt as a $V$-belt connected to a shaft and driven by an electric motor. Then the workpiece is brought closer to the mattress axis and then pressed forward until the desired profile is formed. The design of this multidimensional pipe notcher engine is divided into three stages. The first stage is the design concept and component planning, followed by the manufacturing stage and the last stage is machine testing. From the design results, it is found that this multi-dimensional pipe notcher machine uses an electric motor $0.5 \mathrm{HP}$ and a rotation of $1400 \mathrm{rpm}$ while the engine frame uses $4 \times 4 \mathrm{~cm}$ angle iron. After testing the machine can work properly. To check a 3/4 inch pipe it takes 0.335 minutes, while for a 1 inch pipe it takes 1.075 minutes. Meanwhile, the profiles made using this machine are capable of forming angles between $0^{\circ}$ to $30^{\circ}$.
\end{abstract}

Penulis korespondensi,

Email: iswanto@umsida.ac.id 
Keywords: Design, pipe notcher machine, sandpaper belt

\section{PENDAHULUAN}

Beberapa tahun terakhir, pipa baja tahan karat berdinding tipis telah digunakan semakin luas di industri permesinan. Yang disebut stainless steel berdinding tipis adalah sejenis pipa baja tahan karat yang perbandingan ketebalan dinding dan diameter luarnya tidak lebih dari $6 \%[1,2]$. Dengan pesatnya perkembangan industri manufaktur mesin modern, persyaratan efisiensi produksi dan akurasi pemesinan pada produksi pemotongan pipa baja meningkat secara bersamaan [2, 3]. Di samping itu dengan semakin tingginya pertumbuhan pembangunan perumahan juga berbanding lurus dengan peningkatan penggunaan pipa stainless steel berdinding tipis sebagai bagian dari eksterior maupun interior bangunan perumahan. Faktor yang mempengaruhi presisi dan tidaknya bagian benda kerja saat proses pemesinan adalah: kepresisian pahat mesin, deformasi termal pahat, deformasi pahat, keausan pahat dan deformasi benda kerja $[4,5]$.

Pada umumnya bengkel (work shop) dalam mengerjakan pencoakan pada pipa yang digunakan untuk digabungkan ke pipa lain masih menggunakan cara manual. Sampai saat ini umumnya masih menggunakan cara lama dengan menggunakan mesin gerinda tangan, yang mengakibatkan hasilnya yang kurang presisi. Hal ini dilakukan karena mesin pencoak pipa yang ada harganya masih relatif mahal. Maka dari itu diperlukan alat yang dapat membantu mempercepat proses produksi sehingga mampu menghasilkan produk dalam jumlah banyak dengan waktu yang lebih singkat dengan harga yang terjangkau [6].

Penelitian yang telah dilakukan sebelumnya antara lain: pembuatan mesin yang dilakukan oleh Rofarsyam yaitu Pembuatan mesin amplas sistem sabuk penggerak motor listrik [7] dan pembuatan mesin yang dilakukan oleh Arief Ikma Putra dkk, yaitu Rancang bangun mesin amplas dengan sistem mekanis belt [8]. Pada penelitian tersebut sabuk amplas yang digerakkan oleh motor listrik digunakan untuk melakukan proses pengamplasan. Pada penelitian kali ini, rancang bangun mesin pencoak pipa multi dimensi ini sabuk amplas yang berputar akan digunakan untuk proses mencoak pipa (pemotongan pipa dengan ujung berbentuk profil) sebelum dilakukan penggabungan dan pengelasan dengan pipa yang lain. Cara kerja mesin ini yaitu sabuk amplas dihubungkan dengan poros yang diputar oleh motor listrik yang berkapasitas 0,5 HP dan dengan putaran $1400 \mathrm{rpm}$. Benda kerja didekatkan pada poros matras kemudian benda kerja ditekan maju untuk membentuk profil yang diinginkan.

Pada rancang bangun mesin pencoak pipa multi dimensi ini, perhitungan komponen utamanya antara lain: daya motor listrik, diameter poros dan panjang sabuk amplas. Untuk menghitung daya motor terlebih dahulu menghitung torsi yang terjadi saat mesin bekerja. Untuk menghitung torsi digunakan rumus [9]:

$$
\mathrm{T}=\mathrm{F} \times \mathrm{R}
$$

dimana:

$$
\begin{aligned}
& \mathrm{T}=\operatorname{Torsi}(\mathrm{N} . \mathrm{m}) \\
& \mathrm{F}=\operatorname{Gaya}(\mathrm{N}) \\
& \mathrm{R}=\operatorname{Jari}-\text { jari poros }(\mathrm{m})
\end{aligned}
$$

Sehingga daya motor dapat diperoleh dengan menggunakan rumus [9]:

$$
\mathrm{P}=\mathrm{T} \frac{2 \cdot \pi \cdot n}{60}
$$

dimana:

$\mathrm{P}=$ Daya motor $(\mathrm{Watt})$

$\mathrm{T}=$ Torsi (N.m)

$\mathrm{n}=$ putaran motor (rpm)

Sedangkan untuk menghitung diameter poros menggunakan rumus [10]: 
dimana:

$$
\mathrm{d}_{\mathrm{s}}=\left[\frac{5,1}{\tau \mathrm{a}} \mathrm{K}_{\mathrm{t}} \cdot \mathrm{C}_{\mathrm{b}} \cdot \mathrm{T}\right]^{1 / 3}
$$

$$
\begin{aligned}
& \mathrm{d}_{\mathrm{s}}=\text { Diameter poros }(\mathrm{mm}) \\
& \tau \mathrm{a}=\text { Tegangan geser }\left(\mathrm{kg} / \mathrm{mm}^{2}\right) \\
& \mathrm{K}_{\mathrm{t}}=\text { Faktor koreksi momen puntir } \\
& \mathrm{C}_{\mathrm{b}}=\text { Faktor lenturan } \\
& \mathrm{T}=\text { Momen punter }(\mathrm{kg} \cdot \mathrm{mm})
\end{aligned}
$$

\section{METODE}

Pada penelitian ini konsep yang akan digunakan adalah membuat rancang bangun mesin pencoak pipa multi dimensi. Mesin ini dilengkapi dengan busur derajat pada sebuah ragum yang berfungsi untuk menentukan sudut pipa yang akan di coak dengan mesin ini. Ada tiga tahapan utama yang dilakukan pada penelitian ini. Tahap pertama adalah perancangan desain mesin pencoak pipa multi dimensi. Perancangan desain mesin pencoak pipa multi dimensi dilakukan untuk mengetahui performa apakah design yang dibuat sudah sesuai atau belum. Pada tahap ini selain menentukan desain yang dipilih juga dilakukan perhitungan pada masing-masing komponen mesin, diantaranya: perhitungan daya motor listrik, perhitungan transmisi, penentuan panjang sabuk, perancangan poros, perhitungan bantalan dan perhitungan beban ekuivalen.

Tahap kedua adalah pembuatan mesin pencoak pipa multi dimensi. Sedangkan tahap ketiga adalah pengujian terhadap mesin pencoak pipa multi dimensi. Pada tahap pengujian, ada tiga unsur yang akan diuji yaitu: menghitung waktu pemakanan, menghitung berat sabuk amplas sebelum dan sesudah digunakan dan pengujian sudut yang dapat dibuat.

\section{HASIL DAN PEMBAHASAN}

\subsection{Konsep Desain dan Perencanaan Komponen}

Pada tahap ini dilakukan pembuatan dan pemilihan desain yang sesuai serta perencanaan dan perhitungan komponen dari mesin pencoak pipa multi dimensi. Desain yang dipilih dari mesin pencoak pipa multi dimensi seperti terlihat pada gambar 1 .

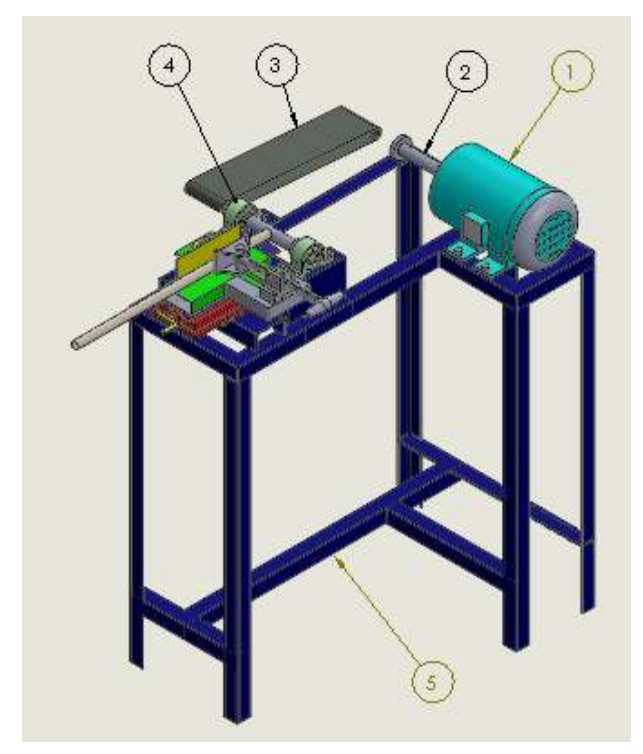

Gambar 1. Desain mesin pencoak pipa

Keterangan gambar:

1. Motor listrik 

2. Poros
3. V-Belt
4. Bearing
5. Rangka

\subsubsection{Perhitungan Daya Motor Listrik}

Untuk menghitung daya motor listrik terlebih dahulu menghitung torsi yang terjadi saat mesin bekerja, untuk menghitungnya dengan menggunakan rumus [10]:

$$
\mathrm{T}=\mathrm{F} \times \mathrm{R}
$$

dimana:

$$
\begin{aligned}
& \mathrm{T}=\operatorname{Torsi}(\mathrm{N} . \mathrm{m}) \\
& \mathrm{F}=\operatorname{Gaya}(\mathrm{N}) \\
& \mathrm{R}=\operatorname{Jari}-\mathrm{jari} \operatorname{poros}(\mathrm{m})
\end{aligned}
$$

Sedangkan diketahui:

$$
\begin{aligned}
& \text { Massa benda } \quad=0,25 \mathrm{~kg} \\
& \text { Massa beban tekanan gaya }=0,25 \mathrm{~kg} \\
& \mathrm{R}=12,35 \mathrm{~mm}=0,01235 \mathrm{~m}
\end{aligned}
$$

Sedangkan,

$$
\begin{aligned}
\mathrm{F} & =(\text { Massa benda }+ \text { Massa beban tekanan gaya }) \times \mathrm{g} \\
& =(0,25+0,25) \times 9,8 \mathrm{~m} / \mathrm{s}^{2} \\
& =4,9 \mathrm{~N}
\end{aligned}
$$

Sehingga:

$$
\begin{aligned}
\mathrm{T} & =4,9 \times 0,01235 \\
& =0,0605 \text { N.m }
\end{aligned}
$$

Untuk mengetahui daya listrik yang digunakan untuk memutar poros dengan cara menghitung torsi motor yang digunakan, yaitu motor 0,5 HP dan putaran $1400 \mathrm{rpm}$.

$$
\mathrm{P}=\mathrm{T} \frac{2 \cdot \pi \cdot n}{60}
$$

dimana:

$$
\begin{aligned}
& \mathrm{P}=\text { Daya motor }(\text { Watt }) \\
& \mathrm{T}=\text { Torsi }(\mathrm{N} . \mathrm{m}) \\
& \mathrm{n}=\text { putaran motor }(\mathrm{rpm})
\end{aligned}
$$

karena $1 \mathrm{HP}=745$ Watt, maka $0,5 \mathrm{HP}=372 \mathrm{Watt}$

sehingga:

$$
\begin{aligned}
& 372=\mathrm{T} \frac{2 \cdot \pi \cdot 1400}{60} \\
& \mathrm{~T}=\frac{372}{146,6}=2,54 \mathrm{~N} . \mathrm{m}
\end{aligned}
$$

Jadi torsi pada motor listrik lebih besar dibandingkan dengan torsi pada mesin coak pipa, yaitu 2,54 > 0,0605. Dengan demikian motor listrik dengan kapasitas 0,5 HP mampu untuk digunakan memutar amplas.

\subsubsection{Perhitungan Transmisi}

Dalam melakukan perhitungan transmisi, data-data komponen yang sudah diketahui untuk bahan perhitungan adalah: 
Motor yang digunakan $\quad=0,5 \mathrm{HP}$

Diameter poros penggerak $\left(\mathrm{D}_{1}\right) \quad=24,7 \mathrm{~mm}=0,0247 \mathrm{~m}$

Diameter poros yang digerakkan $\left(\mathrm{D}_{2}\right)=25,4 \mathrm{~mm}=0,0254 \mathrm{~m}$

Putaran pully penggerak $\left(\mathrm{n}_{1}\right) \quad=1400 \mathrm{rpm}$

maka,

$$
\begin{aligned}
n_{2} & =\frac{D_{1} \cdot n_{1}}{D_{2}} \\
& =\frac{0,0247 \times 1400}{0,0254} \\
& =1361 \mathrm{rpm}
\end{aligned}
$$

Sehingga kecepatan keliling pully penggerak $\left(\mathrm{V}_{\text {pully }}\right)$

$$
\begin{aligned}
\mathrm{Vp} & =\frac{\pi \cdot \mathrm{D}_{1} \cdot \mathrm{n}_{1}}{60} \\
& =\frac{3,14 \times 0,0274 \times 1400}{60} \\
& =1,81 \mathrm{~m} / \mathrm{s}
\end{aligned}
$$

\subsubsection{Penentuan Panjang Sabuk}

Untuk mengetahui berapa panjang sabuk amplas yang digunakan dilakukan perhitungan panjang V-belt dengan menggunakan rumus:

$$
\mathrm{L}=2 \mathrm{c}+\frac{\pi}{2}(\mathrm{Dp}+\mathrm{dp})+\frac{1}{4 \mathrm{c}}(\mathrm{Dp}-\mathrm{dp})^{2}
$$

Sedangkan dari data diameter pully dengan jarak poros motor diketahui:

$$
\begin{aligned}
& \mathrm{D}_{\mathrm{p}}=24,7 \mathrm{~mm} \\
& \mathrm{~d}_{\mathrm{p}}=25,4 \mathrm{~mm} \\
& \mathrm{C}=275 \mathrm{~mm}
\end{aligned}
$$

Sehingga:

$$
\begin{aligned}
\mathrm{L} & =2 \cdot 275+\frac{\pi}{2}(25,5+24,7)+\frac{1}{4 \cdot 275}(25,5-24,7)^{2} \\
& =629 \mathrm{~mm}
\end{aligned}
$$

\subsubsection{Perancangan Poros}

Poros pada mesin pencoak pipa meneruskan daya dari motor listrik sebesar 0,5 $\mathrm{Hp}$ dan mendapatkan beban dari sabuk amplas yang berputar.

Diketahui daya yang ditransmisikan:

$$
\begin{aligned}
& \mathrm{P}=0,5 \mathrm{Hp}=0,372 \mathrm{KW} \\
& \mathrm{n}=1400 \mathrm{rpm} \\
& \mathrm{fc}=1,5
\end{aligned}
$$

Untuk menentukan daya rencana $\mathrm{Pd}(\mathrm{kw})$ sebagai patokan adalah [9]:

$$
\mathrm{Pd}=\mathrm{Fc} . \mathrm{P}(\mathrm{kw})
$$

dimana:

$\mathrm{Pd}=$ daya yang direncanakan $(\mathrm{kw})$

$\mathrm{Fc}=$ faktor koreksi

$\mathrm{P}=$ daya yang ditransmisikan $(\mathrm{kw})$

Karena diketahui daya yang ditransmisikan:

$$
\mathrm{P}=0,5 \mathrm{Hp}=0,372 \mathrm{KW}
$$


$\mathrm{n}=1400 \mathrm{rpm}$

$\mathrm{fc}=1,5$

maka,

$$
\begin{aligned}
\mathrm{Pd} & =\mathrm{Fc} \times \mathrm{P} \\
& =1,5 \times 0,372 \\
& =0,558 \mathrm{kw}
\end{aligned}
$$

Untuk menghitung torsi pada poros penerus yang terjadi karena putaran motor digunakan rumus [10]:

$$
\mathrm{T}=9,74 \cdot 10^{5} \times \frac{\mathrm{P}_{\mathrm{d}}}{\mathrm{n}}
$$

Karena diketahui:

maka:

$$
\begin{array}{ll}
\mathrm{P}_{\mathrm{d}}(\text { daya rencana motor }) & =0,558 \mathrm{Kw} \\
\mathrm{n}(\text { putaran poros }) & =1400 \mathrm{rpm}
\end{array}
$$

$$
\begin{aligned}
\mathrm{T} & =9,74 \cdot 10^{5} \times \frac{0,558}{1400} \\
& =388,2 \mathrm{~N} . \mathrm{m}
\end{aligned}
$$

Untuk menghitung tegangan geser yang diijinkan digunakan rumus [9]:

Dimana:

$$
\tau \mathrm{a}=\frac{\sigma_{B}}{\mathrm{sf}_{1} \cdot \mathrm{sf}_{2}}
$$

$$
\begin{array}{ll}
\tau \mathrm{a} & =\text { Tegangan geser yang diijinkan }\left(\mathrm{kg} / \mathrm{mm}^{2}\right) \\
\sigma_{\mathrm{B}} & =\text { Kekuatan tarik }\left(\mathrm{kg} / \mathrm{mm}^{2}\right) \\
\mathrm{sf}_{1} \text { dan } \mathrm{sf}_{2} & =\text { Faktor keamanan }
\end{array}
$$

Bahan poros yang digunakan untuk perencanaan mesin pencoak pipa yaitu menggunakan baja St 37 yang memiliki kekuatan tarik $\left(\sigma_{\mathrm{B}}\right) 37 \mathrm{~kg} / \mathrm{mm}^{2}$ dengan $\mathrm{sf}_{1}=6,0$ dan $\mathrm{sf}_{2}=3,0$.

Sehingga:

$$
\tau \mathrm{a}=\frac{37}{6 \times 3}
$$

Jadi tegangan geser yang diijinkan sebesar $2,05 \mathrm{~kg} / \mathrm{mm}^{2}$

Untuk menghitung diameter poros dengan menggunakan rumus:

dimana:

$$
\mathrm{d}_{\mathrm{s}}=\left[\frac{5,1}{\tau \mathrm{a}} \mathrm{K}_{\mathrm{t}} \cdot \mathrm{C}_{\mathrm{b}} \cdot \mathrm{T}\right]^{1 / 3}
$$

$$
\begin{aligned}
& \mathrm{d}_{\mathrm{s}}=\text { Diameter poros }(\mathrm{mm}) \\
& \tau \mathrm{a}=\text { Tegangan geser }\left(\mathrm{kg} / \mathrm{mm}^{2}\right) \\
& \mathrm{K}_{\mathrm{t}}=\text { Faktor koreksi momen puntir } \\
& \mathrm{C}_{\mathrm{b}}=\text { Faktor lenturan } \\
& \mathrm{T}=\text { Momen punter }(\mathrm{kg} \cdot \mathrm{mm})
\end{aligned}
$$

Apabila diketahui Momen puntir $\left(\mathrm{K}_{\mathrm{t}}\right)=1,5$ dan faktor lenturan $\left(\mathrm{C}_{\mathrm{b}}\right)=2$, maka:

$$
\begin{aligned}
\mathrm{d}_{\mathrm{s}} & =\left[\frac{5,1}{2,05} \cdot 1,5 \cdot 2 \cdot 388,2\right]^{1 / 3} \\
& =14,26
\end{aligned}
$$

Sehingga diameter poros yang digunakan sebesar $15 \mathrm{~mm}$. 


\subsubsection{Perhitungan Bantalan}

Bantalan yang akan digunakan adalah Tipe 6204 yang memiliki spesifikasi [9]:

Jenis bantalan = bantalan gelinding

Nomor bantalan $\quad=6204$

(D) diameter luar $\quad=47 \mathrm{~mm}$

( $\mathrm{d}$ ) diameter dalam $=20 \mathrm{~mm}$

(b) lebar bantalan $\quad=14 \mathrm{~mm}$

( $\mathrm{r}$ ) jari bantalan $\quad=1,5 \mathrm{~mm}$

(c) kapasitas nominal dinamis spesifik $=1000 \mathrm{~kg}$

( co ) kapasitas nominal statis $\quad=635 \mathrm{~kg}$

Bantalan pada mesin pencoak pipa diberikan putaran $1400 \mathrm{rpm}$, jadi semakin tinggi putarannya maka umur bantalannya semakin kecil.

3.1.6. Perhitungan Beban Ekuivalen $\left(\mathrm{P}_{\mathrm{r}}\right)$

$$
\mathrm{P}_{\mathrm{r}}=\mathrm{XVF}_{\mathrm{r}}+\mathrm{YF}_{\mathrm{a}}
$$

dimana :

$\mathrm{P}_{\mathrm{r}}=$ gaya ekivalen $(\mathrm{kg})$

$\mathrm{X}=$ faktor beban radial

$\mathrm{V}=$ faktor rotasi bantalan (nilainya $=1,0$ jika bantalan ring dalam yang berputar dan nilainya $=1,2$ apabila bantalan ring luar yang berputar)

$\mathrm{F}_{\mathrm{r}}$ = gaya radial $(\mathrm{kg})$

$\mathrm{Y}=$ faktor beban aksial

$\mathrm{F}_{\mathrm{a}}=$ gaya aksial $(\mathrm{kg})$

Karena nilai $\mathrm{x}=1$ dan $\mathrm{y}=0$, maka untuk beban radial persamaannya menjadi:

$$
\mathrm{P}=\mathrm{V} \times \mathrm{Fr}
$$

Untuk menentukan beban radial pada poros digunakan rumus [10]:

$$
\mathrm{T}=\mathrm{F}_{\mathrm{r}} \times \mathrm{R}
$$

Dimana:

$$
\begin{aligned}
& \mathrm{T}=\operatorname{torsi}(\mathrm{Nm}) \\
& \mathrm{F}_{\mathrm{r}}=\text { gaya }(\mathrm{N}) \\
& \mathrm{R}=\text { jari-jari poros }(\mathrm{m})
\end{aligned}
$$

Apabila diketahui nilai dari:

$$
\begin{aligned}
\mathrm{T} & =417,4 \mathrm{Nm} \\
\mathrm{R} & =12,35 \mathrm{~mm}=0,01235 \mathrm{~m}
\end{aligned}
$$

Sehingga:

$$
\begin{aligned}
& \mathrm{F}_{\mathrm{r}}=\frac{417,4}{12,35} \\
& \mathrm{Fr}=33,7 \mathrm{~kg}=337 \mathrm{~N}
\end{aligned}
$$

Jadi untuk menentukan beban ekuivalen dinamis:

$$
\mathrm{Pr}=\mathrm{X} \times \mathrm{V} \times \mathrm{Fr}+\mathrm{Y} \times \mathrm{Fa}
$$

Karena gaya aksial $\mathrm{Fa}=0$, maka;

$$
\begin{aligned}
\mathrm{P} & =\mathrm{X} \times \mathrm{V} \times \mathrm{Fr} \\
& =1 \times 1 \times 337 \\
& =337 \mathrm{~N}
\end{aligned}
$$




\subsection{Pembuatan}

Berdasarkan hasil konsep desain dan perencanaan serta perhitungan komponen selanjutnya dijadikan dasar untuk proses pembuatan produk. Dari proses pembuatan yang dilakukan dihasilkan mesin pencoak pipa multi dimensi seperti terlihat pada gambar 2 .

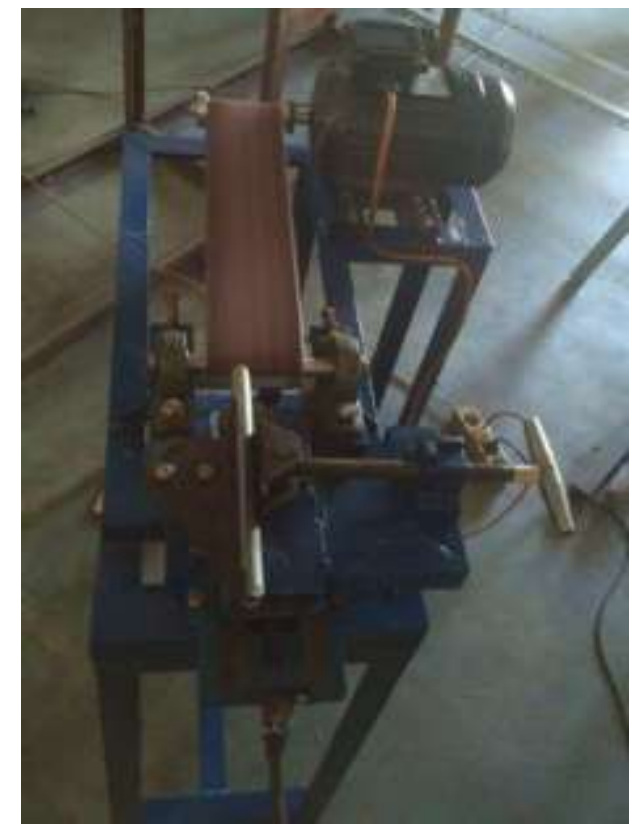

Gambar 2. Mesin pencoak pipa multi dimensi

\subsection{Pengujian Mesin}

Pengujian mesin pencoak pipa multi dimensi dilakukan dengan dua macam pengujian, yaitu pengujian performa mesin dan pengujian sudut dimensi. Sedangkan untuk benda kerja (pipa) yang diuji juga menggunakan dua macam variasi diameter pipa, yaitu dengan menggunakan pipa berdiameter 3/4 inch dan 1 inch.

\subsubsection{Pengujian Performa Mesin}

Hasil pengujian performa mesin pencoak pipa multi dimensi dengan parameter pengujian waktu yang dibutuhkan untuk melakukan proses pencoakan dan berat amplas yang hilang selama digunakan dalam proses pencoakan ditunjukkan pada tabel 1 .

Tabel 1. Pengujian waktu pencoakan dan berat amplas

\begin{tabular}{ccccc}
\hline \multirow{2}{*}{$\begin{array}{c}\text { Diameter } \\
\text { pipa (inch) }\end{array}$} & Pengujian & $\begin{array}{c}\text { Waktu } \\
\text { (menit) }\end{array}$ & & \multicolumn{2}{c}{ Berat amplas (gram) } \\
\hline \multirow{2}{*}{$3 / 4$} & 1 & 0,34 & 99,62 & 94,30 \\
& 2 & 0,5 & 99,66 & 93,60 \\
1 & 1 & 1 & 99,63 & 92,08 \\
& 2 & 1,15 & 99,62 & 93,40 \\
\hline
\end{tabular}

Dari hasil pengujian mesin pencoak pipa multi dimensi diperoleh waktu rata-rata yang dibutuhkan untuk mencoak pipa dengan diameter 3/4 inch adalah 0,42 menit (25,2 detik), sedangkan untuk mencoak pipa dengan diameter 1 inch membutuhkan waktu rata-rata selama 1,075 menit (64,5 detik). Sedangkan untuk melakukan pencoakan pipa berdiameter 3/4 inch berat amplas yang hilang seberat 5,69 gram dan apabila digunakan untuk mencoak pipa dengan diameter 1 inch terdapat 6,885 gram amplas yang hilang. Sehingga rata-rata data pengujian dapat disajikan dalam grafik seperti pada gambar 3 . 


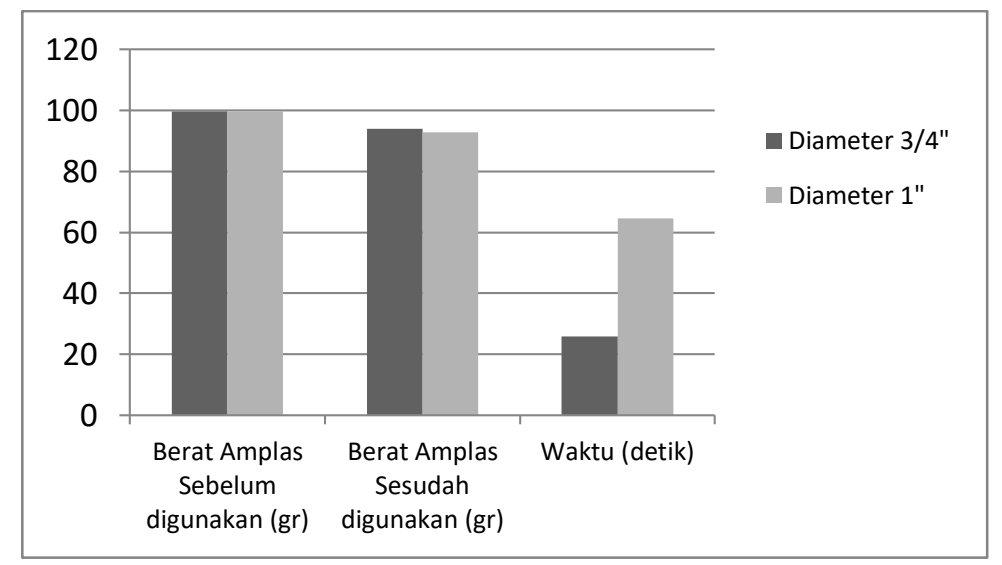

Gambar 3. Grafik Pengujian waktu pencoakan dan berat amplas

\subsubsection{Pengujian Sudut}

Setelah melalui beberapa tahap pengujian, mesin pencoak pipa multi dimensi ini hanya mampu membentuk profil dengan sudut $0^{\circ}$ sampai dengan $30^{\circ}$. Untuk membentuk profil lebih dari $30^{\circ}$ mesin ini perlu pengembangan lebih lanjut.

\section{SIMPULAN}

Dari hasil keseluruhan proses rancang bangun mesin pencoak pipa multi dimensi, maka dapat diperoleh kesimpulan sebagai berikut:

1. Berdasarkan perancangan komponen dan pembuatan, mesin pencoak pipa memiliki spesifikasi: menggunakan rangka besi siku ukuran $4 \mathrm{x} 4 \mathrm{~cm}$, daya motor berkapasitas 0,5 Hp dengan kecepatan putaran $1400 \mathrm{rpm}$.

2. Mesin pencoak pipa multi dimensi menggunakan sabuk amplas sebagai V-belt yang berfungsi sebagai sarana alat pencoak pipa.

3. Setelah dilakukan pengujian mesin bisa bekerja dengan baik. Untuk mencoak pipa dengan diameter 1 inch membutuhkan waktu selama 1,075 menit, sedangkan untuk mencoak pipa ukuran 3/4 inch dibutuhkan waktu selama 0,42 menit. Sementara itu profil sudut yang dapat dibentuk menggunakan mesin ini berkisar dari $0^{\circ}$ sampai dengan $30^{\circ}$.

\section{DAFTAR PUSTAKA}

[1] Black, J. T. \& Kohser, R. A., De Garmo's Materials and Processes in Manufacturing, $12^{\text {th }}$ Edition, John Wiley \& Sons, 2017.

[2] J. Yi, Y. Qian, Z. Shang, Z. Yan, and Y. Jiao, Design of Cutting Head for Efficient Cutting Machine of Thin-walled Stainless Steel Pipe, Procedia Eng., vol. 174, pp. 1276-1282, 2017, doi: 10.1016/j.proeng.2017.01.302.

[3] Rochim, Taufiq, Teori dan Teknologi Proses Pemesinan, ITB, Bandung, 2007.

[4] E. M. Trent \& P. K. Wright, Metal Cutting, $3^{\text {rd }}$ Edition, Butterworth Heinemann, Boston, 2000.

[5] Iswanto, M. F. Firmansyah, and Mulyadi, Effect of the Cutting Angle and the Depth of Cut Toward Wear of Carbide Tool on the Lathe, J. Phys. Conf. Ser., vol. 1594, p. 012027, 2020, doi: 10.1088/1742-6596/1594/1/012027.

[6] Mulyadi, Iswanto, Dwi Setyo Utomo, Elly Antarisma, Rancang Bangun Jig Penyambung Pipa Multidimensi, Prosiding Senaspro, Universitas Muhammadiyah Malang, 309-318, 2017.

[7] R. Rofarsyam, Pembuatan Mesin Amplas Sistem Sabuk Penggerak Motor Listrik, J. 
Rekayasa Mesin, vol. 13, no. 3, p. 73, 2018, doi: 10.32497/rm.v13i3.1285.

[8] Arief Ikma Putra, Yuli Yetri, Maimuzar, Rancang bangun mesin amplas dengan sistem mekanis belt, Jurnal Teknik Mesin, 11, 2, 63-69, 2018.

[9] Khurmi, R. S., Gupta, J. K., Machine Design, Urasia Publishing House, New Delhi, 1979.

[10] Sularso, Suga, K., Dasar Perencanaan dan Pemilihan Elemen Mesin, Pradnya Paramita, Jakarta, 1978. 